\title{
On Continuing Professional Development for Prognostics and Health Management Practitioners
}

\author{
Jeff Bird \\ PHM Society Committee on Education and Professional Development, and \\ TECnos Consulting, Ottawa, Ontario K1J $9 B 3$ Canada \\ jeff.bird@magma.ca
}

\begin{abstract}
The Prognostics and Health Management Society has as one its principles the advancement of PHM as an engineering discipline. A key factor in this advancement would be helping PHM practitioners to be life-long learners and professionals. The following professional organizations are surveyed to compile best practices in the domain of Continuing Professional Development (CPD): Professional Engineers and Geoscientists, Medical Doctors, Lawyers, Vibration Specialists and Aircraft Mechanics. Key aspects of these systems are compiled covering accepted activities, requirements and features relevant to the PHM domain. A proposed PHM CPD Guideline is presented for discussion. The framework includes a PHM CPD Basis for Recognition, Recommended PHM CPD Activity Types, Quantitative Goals, and Guidelines for Use. In addition, several issues are presented that should be addressed if and when such a system is considered. A way forward is proposed to include evaluation by the PHM Society in a workshop at the Annual Conference of the PHM Society.
\end{abstract}

\section{BACKGROUND}

Prognostics and Health Management is a diverse, multidisciplinary domain with rapidly evolving capability needs.

As well, initial education and training in many disciplines must be complemented by specialized and professional development over a career.

Benchmarks are being developed under the Society's PHM Capability Taxonomy for career planners, employers and training developers to facilitate transitions between mastery levels within a discipline. The stakeholders wanting a stream of qualified practitioners include academia, industry

\footnotetext{
Jeff Bird. This is an open-access article distributed under the terms of the Creative Commons Attribution 3.0 United States License, which permits unrestricted use, distribution, and reproduction in any medium, provided
}

and the public sector/government.

The PHM community has examined standardization and professional certification recognizing the benefits but also the complexity and overhead. It is clear that Continuing Professional Development (CPD) has become a key requirement of a number of professional organizations, e.g. Medical Associations and Professional Engineers and Geoscientists. However, mandatory CPD requirements are not widely well received.

\section{2. ОВJECTIVE}

To aid the PHM community in becoming lifelong learners, it is proposed to develop with the various stakeholders:

a) A compilation of recommended types of PHM professional development in skills and mastery levels defined by the PHM Society Capability Taxonomy (Bird, Madge \& Reichard, 2014)

b) Guidelines on quantitative goals for professional development over practical time periods

c) Guidelines for preparing, evaluating and reporting plans and achievements.

The intent is to develop a voluntary system that would be used by PHM practitioners because it is of benefit in its flexibility and encouragement of depth as well as breadth of development.

The PHM Continuing Professional Development Guidelines and the PHM Capability Taxonomy should be usable by the PHM community.

a) Practitioners for career planning and implementation: Plan broad-based education and professional development progressions and understand skills and capabilities required and ways to achieve them.

b) Employers: A job description could be kept current with the employee to include a capabilities list from various areas with desired mastery levels matched to 


\section{COMMUNICATIONS}

a nominal continuing development plan. Evaluation schemes could reference mastery levels to be demonstrated or developed with development goals achieved. Professional development transitions could be defined and matched to training and in-house assignments.

c) Technology, training and professional development course developers: Identify niche areas and descriptors for likely pre-requisites available and new competencies to be acquired.

\section{Continuing Professional Development Current PraCTICE}

A number of professional associations have developed continuing professional development schemes. Several of these are mandatory for the professionals to maintain their status as practitioners in regulated fields with evolving knowledge and skills. This section summarizes the key features of some representative CPD schemes in existence, towards the selection of the best practices for consideration as a PHM CPD Guideline.

\subsection{Engineers and Geoscientists}

The Association of Professional Engineers and Geoscientists of Alberta (Canada) have developed a mandatory CPD program, which requires practitioners/licensees to plan, conduct and document activities each year. These reports are subject to audit. Details are provided at APEGA (2014) but key aspects of their scheme can be summarized.

Activity Types: Their designated activities include: Professional Practice, Formal (training) Activity, Informal (training) Activity, Participation (in peer interaction and panels), Presentations and Contributions to Knowledge (standards, papers, patents).

Requirements: 80 hours per year (in at least 3 activity areas) or 240 hours over three years.

Features: They provide guidance for employers to be engaged but emphasize that the responsibility rests with the practitioner. Some credit for time spent in non-technical community work is an interesting aspect of their view of the role of a professional group in society.

This group is especially relevant to the PHM domain as the science and applications used by professional engineers and oil and gas professionals are ones of evolving technology, standards and business demands. Credit for contributions to community activities could be seen to enhance the role of the PHM Society and its associated organizations like sponsors in the larger community.

\subsection{Medical Doctors}

The American Medical Association has developed an extensive CPD program for Continuing Medical Education (CME) to: "ensure physicians meet the needs of a continuously evolving system, provide professional satisfaction and sustainable practices." The CPD system is based on accredited third party content providers as well as directly accrediting members (AMA, 2010). Their program rewards practitioners who achieve levels of accredited CPD activities with a Physician's Recognition Award. The State licensing boards are also stakeholders in accreditation of skills and knowledge and appear to be linked into CPD activities. Details of the AMA program are provided at AMA (2010) but the key aspects can be summarized.

Activity Types: Activities fall into several categories. Category 1 types: Live (training as student/faculty) Activity, Enduring Materials (packaged courses), Journal Editor/Author/Reviewer, Poster Author, Test Item Writing, Manuscript Review, Performance Improvement (structured learning exercise), Internet Self Directed Learning, and Advanced Degrees or Certificates. Category 2 types are less structured (accredited by the practitioner): Teaching, Unstructured On-line Searching and Learning, Reading Authoritative Literature, Consultation with Peers and Experts, Small Group Discussions, Self-Assessment, Medical Writing, Preceptorship, Research, and Peer Review and Quality Assurance.

Requirements: Award - 50 credits/year (20 Category 1 and 30 Category 1 or 2). Award with Commendation - 90 credits/year (60 Category 1 and 30 Category 1 or 2). Activities can generate 1-50 credits per activity, e.g. 1 for student in a live course, 3 for a review, 5 for a poster, 10 for an article, 25 for a degree. Category 2 activities generate 1 credit per hour. Half of the credit must be in the practitioner's specialty, i.e. not all can be in business practices or soft skills.

A State Medical Society requirement for a CME Certificate (PAMED, 2014) may be 100 hours of CME and 40 AMA Category credits with 12 Category 1/Category 2 credits in patient safety and risk management. The state licensing board required (only) 20 Category 1 credits per two-year cycle. The state society aims to meet the AMA and the licensure requirements together in a CME certificate.

Features: They require verification of training at four levels: attendance, satisfactory completion of course objectives, readiness to perform the work under proctor supervision and competence to perform the procedure without supervision. Only first authors of papers seem to get credit.

Clearly the consequences of medical practitioner error are more serious than for a PHM practitioner but features of this system are likely key to confidence in the results and in the practitioner themselves. Their system is quite detailed but recognizes the complexity and breadth of useful activities: 
most content is accredited by others with evaluations but the Category 2 activities can be self-reported. The approach of an award incentive by the national organization versus mandatory reporting to the licensing organization should be of interest to the PHM community.

\subsection{Lawyers}

The legal profession is another one with evolving knowledge and experience. Many law societies which govern licensing require CPD. As an example, the requirements of the Alberta Law Society are available at LSA (2014) with some key details here.

Activity Types: The practitioners are responsible for selecting types appropriate to their practice that meet broad definitions to be interpreted by the practitioners themselves to be: "relevant to the professional needs of a lawyer, pertinent to long-term career interests as a lawyer, in the interests of the employer of a lawyer or related to the professional ethics and responsibilities of lawyers." Suggestions and ideas are given covering courses, conferences, post graduate courses, teaching, writing, study groups and mentoring. They provide some suggestions for activities for junior, mid-career, research, in house council, senior, semi-retired and new entry lawyers.

Requirements: Activities must contain "significant substantive, technical, practical or intellectual content." There are no quantitative standards and the Society does not accredit course providers.

Features: Their website provides tools to identify CPD goals, evaluate past year activities, create and record new year activities in a plan and declare it officially. They include a Resource Bank, which is a list of links to sources of CPD content. Currently the Law Society is looking at developing "a more robust regulatory framework to ensure that lawyers are held accountable for developing and implementing high quality CPD Plans." They provide some suggestions for types of activities for different career points including researchers and sole practitioners.

This practitioner-driven, low overhead system should be of interest to the PHM community. Based on their current development work it appears that more structure is required for accountability and implementation of good CPD plans. Providing sample activities for specific career points is worth emulating.

\subsection{Vibration Specialists}

Historically the vibration and mechanical condition monitoring and diagnosis field could be considered the birthplace of PHM practices. So CPD in that domain is of direct interest to the PHM Society. The Vibration Institute (VI) is "dedicated to the dissemination of practical information on evaluating machinery behavior and condition" (VI, 2014). The VI vibration analysts' certification program is formal, and accredited by the American National Standards Institute. "For certified vibration analysts, it ensures technical competence and a measurement for advancing careers. For employers, certification validates employees' skills and knowledge that ultimately result in better service, support and customer satisfaction grounded in safe and effective practices." Some details of the VI program are given at VI (2014) but can be summarized here.

Activities: Evidence of professional practice includes work experience, and Vibration-Related Technical Activities including: Documented Training, Meeting and Conference Attendance (VI Chapter and committee meetings, VI, MFPT and ASME conferences or other similar meetings) and Presentations and Publications (original documented, vibration-related papers, articles in a recognized publication publically available).

Requirements: Analysts are to remain certified by attesting to their activity each year, and every five years must recertify either by repeating exams or by providing evidence of "continuing education experience, training and/or technical activity." Points for renewal can be earned for vibration-related activities and range from 24 to 36 points (Analyst Levels I-IV) of which up to 20 can be met by accumulated experience, e.g. 5 years with at least $60 \%$ of time doing vibration related work. CPD activities are credited at certain points per hour, day or item. Notably they credit 2 pts for a technical presentation and 3 points for a published article. Maximum credits per year for Documented Training are 16 points, Meeting and Conference Attendance are 16 points, and for presentations and Publications are 16 points.

Features: Experience which can be a major component of the points total is confirmed by a named employer representative and their signature. Credits are generally limited to vibration-related materials which are defined as the body of knowledge in the VI's Certification scheme. Companion technologies outside vibration are severely limited as are equipment maintenance and repair activities, e.g. thermography, oil analysis, ferrography, motor current analysis.

This scheme is of great interest to the PHM Society because it covers a knowledge and skill domain which would be considered to be a subset of PHM. In addition it shows how a formal, four level, certification program has been combined with CPD. The annual Proactive Surveillance Program is in place that captures an attestation by the practitioner with detailed information captured every 5 years. Notably all of the claimed points are certified by the practitioner, although identifying information is documented. Here also the relative value of certain activities may be an issue within the PHM community, e.g. presentation versus published paper. 


\subsection{Aircraft Mechanics}

The US Federal Aviation Administration and industry developed a voluntary incentive program for Aircraft Maintenance Technicians (AMT) to encourage initial and recurrent training (FAA, 2009). Their rationale is: "Continuous participation in the FAA William (Bill) O'Brien Awards Program for regulatory, airworthiness, and safety awareness training will reinforce and promote/foster a high level of professionalism and safety within the industry." The details are provided at FAA (2009) but interesting aspects can be summarized.

Activities: Eligible activities include courses from manufacturers or authorized representatives, air carriers, and FAA, and college/university/technical school level courses. There is Mandatory Core Training on "aviation maintenance accident/incident causal factors, special emphasis items, and regulatory issues." This training is done on-line at the FAA site and time spent counts toward awards.

Requirements: Awards are based on submissions in a calendar year. There are three levels of award for AMTs Certificate of Training- Phase I Bronze (12 hours), Phase II Silver (40 hours) and Phase III Gold ( 80 hours plus a college level course) and two levels for employers AMT Employer- Gold (50\% employee participation) or Diamond Award of Excellence (100\% employee participation).

Features: Both practitioners and their employers can apply for awards on-line in January and February, respectively following the year to be recognized and print certificates from the individual's award history page. The FAA requires at least 60 days to process the confirmation of eligibility.

The concept of recognizing employers with engaged PHM practitioners is interesting as a means of helping to implement CPD plans and to connect employers with the PHM Society. The award template pages could be hosted on the PHM Society webpage but if individual history pages were there too, there would be privacy issues and the overhead of verifying the content if the award was to be sanctioned by the Society.

\section{PHM CPD GUIDELINE FRAMEWORK}

The proposed 'straw man' framework builds on a number of existing ones reviewed while accounting for the unregulated and multi-disciplinary nature of the PHM community. The framework includes a PHM CPD Basis for Recognition, Recommended PHM CPD Activity Types, Quantitative Goals, and Guidelines for Use. A documentation process is also proposed that facilitates practitioner planning and documentation as well as interaction with employers/supervisors.

\subsection{Basis for CPD Recognition}

The goals of a PHM CPD Program could be proposed, following the AMA approach (AMA, 2010), as:

1. To provide recognition for PHM practitioners who regularly participate in CPD;

2. To encourage all practitioners to keep up-to-date and to improve their knowledge and judgment by PHM CPD;

3. To provide reassurance to employers and the public that PHM practitioners are maintaining their competence by regular participation in CPD;

4. To emphasize the PHM Society's position as a leader in PHM CPD;

5. To emphasize the importance of developing more meaningful continuing education opportunities for PHM practitioners; and

6. To strengthen the PHM practitioner's position as a leader in development and implementation teams by focusing attention on their interest in maintaining professional competence.

The proposed approach is that a PHM practitioner could be guided to plan and document CPD activities judged by the PHM community as valuable. This voluntary program would be self-directed by the PHM practitioner but employer engagement would strongly encouraged. Two options are proposed for consideration:

1. Qualitative CPD: Practitioners plan, execute and review their CPD activates based on guidance from the PHM Society; or

2. Accredited CPD Award: When a practitioner achieves a target number of CPD activities hours they would receive a biannual PHM CPD Recognition Award by the PHM Society. PHM CPD Employer Recognition Awards could also be available to employers with significant numbers of awarded practitioners, as identified by the PHM Society.

\subsection{Activity Types}

To guide the life-long learning process for PHM practitioners a suggested list of professional development activities is proposed. The intent is to encourage breadth and depth in the CPD activities by capturing best practices to aid planning by practitioners. Activities would need to have significant and substantive content. The following types of CPD activities and examples are proposed as appropriate to the PHM community:

1. Professional Practice

a. Analysis, planning, evaluation

b. Internal report

c. Influencing the practice of PHM

2. Formal Learning 


\section{COMMUNICATIONS}

a. Organized courses, webinars, seminars and workshops as student or instructor

b. Advanced certificates, degrees, theses or certification

3. Informal Learning

a. Self-directed learning with documentation

b. Consultation with technical experts and peers with documentation

c. Conference attendance with documented summary of learning

d. Technical meeting attendance with documented summary of learning

e. 'Lunch and Learn' activity attendee or leader

4. Contributions to Knowledge

a. External/public codes, standards, papers, white papers, books, patents

b. Conference paper reviewer, review manager

c. Journal reviewer, associate editor, editor

d. Technical program chair or committee

e. Presentations- individual and panel

f. PHM course developer

5. Participation
a. Technical Conference management roles
b. Technical Board or committee roles
c. Mentoring as a mentor or mentee
d. Community service

In each case, the practitioner should ensure that there is some outcome or write-up to capture and document the activity and the associated outcomes. For example, the result of a conference attendance might be their notes on the assessments of gaps, opportunities, significant contacts and key technologies identified directly by the practitioner and compiled from conversations with colleagues, experts or other contacts. Sample lists could be developed for the following PHM practitioner levels, for example: entry level (with and without PhD), mid-career, senior specialist, PHM project manager, PHM program manager, technical fellow, semi-retired.

\subsection{Goals}

Option 1- Qualitative CPD: PHM practitioners would set their own goals and quantitative measures of the CPD content with no external accreditation.

Option 2- Accredited CPD Award: Quantitative goals for a PHM CPD Award would be recommended by the PHM Society for guidance to practitioners. The overhead of a number of annual systems and the need for medium term planning suggest that a two year system may be desirable. For this option, these goals could include:

1. Attain a total of at least X PHM Professional Development hours over two years, and

2. Include activities from at least $Y$ of the five activity types of PHM Professional Development.
Acceptability of the options and reasonable levels for these quantitative goals are to be evaluated through a workshop at the PHM Society's Annual Conference in October 2014 (PHM14). A system of relative levels of value and limits on totals claimed in individual types (as in APEGA (2014) and AMA (2010)) would also be desirable only if it can be kept simple.

\begin{tabular}{|l|c|c|c|c|c|}
\hline \multicolumn{6}{|c|}{$\begin{array}{c}\text { Continuing Professional } \\
\text { Activity Plan and Record }\end{array}$} \\
\hline Date & $\begin{array}{c}\text { Plan } \\
\text { or }\end{array}$ & $\begin{array}{c}\text { Type } \\
\text { (drop- } \\
\text { down } \\
\text { menu) }\end{array}$ & $\begin{array}{c}\text { Description } \\
\text { of the } \\
\text { Activity }\end{array}$ & $\begin{array}{c}\text { Organizer } \\
\text { or } \\
\text { Provider }\end{array}$ & $\begin{array}{c}\text { Number of } \\
\text { CPD Hours }\end{array}$ \\
\hline Done & & & & \\
\hline
\end{tabular}

Table 1. Model for a PHM CPD Activity Record

\subsection{Activity Record}

An activity record could be developed for planned activities and to document completed activities by the practitioner. It could include:

1. Date of the activity,

2. Type of activity,

3. Description of the activity,

4. Organizer or provider of the activity, and

5. Number of Professional Development Hours to be claimed.

A model template for recording activities is given in Table 1.

\subsection{PHM CPD Guideline Suggestions for Use}

The guidelines would benefit from input from early, middle and late career PHM practitioners from diverse sectors to ensure best practices are captured. Guidelines for use might include:

1. PHM practitioners should identify professional development activities to maintain, improve or extend their skills and knowledge. Then they could draft a short and long term plan for their professional development in cooperation with employers. They should assess whether the planned activities are adequate to maintain and/or increase competencies, in reference to the PHM Capabilities Taxonomy.

2. Tabulations of accomplished activities should be prepared and reviewed at year end to identify achievements, balance, gaps, and opportunities. Records should be retained for archival and planning 
purposes. Submissions for awards would be made biannually.

3. Employers should be encouraged to participate (following the APEGA lead) through consultation during development of CPD plans, provision of learning opportunities, assistance in developing job expectations and responsibilities, periodic review of performance and progress, assistance in documenting activities and levels of effort through company performance management systems, and financial support of activities and release time to participate in activities.

4. Guidelines should be regularly reviewed to ensure they are relevant and include evolving opportunities. Samples of typical activities with appropriate complexity and breadth could be provided for entry level, mid-career, senior, semi-retired, academic, technical fellow, and solo practitioners.

5. A Resource Bank of CPD sources could be created on the PHM Society Website. No official accreditation of the providers would be sought. Selected ones might be listed as educational cosponsors like the PHM Society technical co-sponsors.

\section{ISSUES}

The review of CPD systems in use from the perspective of a PHM community has identified some general issues to be examined to establish feasibility and capture best practices:

1. Is there agreement that lifelong learning and CPD are clear desires of PHM practitioners?

2. Is a CPD system a good way of achieving some of the benefits seen in a formal certification or accreditation while minimizing the disadvantages/overheads?

3. Could the community agree on types of PHM CPD activities that would provide guidance to practitioners?

4. Is a non-mandatory compilation of CPD activities useful?

5. Would non-certified/accredited/evaluated activities be acceptable?

6. Would employers encourage participation and incorporate the scheme into planning?

7. Would employers wish to be recognized for the participation of their employees when the PHM Society recognizes a significant number of their employees have attained CPD recognition?

8. Would academic or training organizations be able to get involved?
The two options for a PHM scheme could be considered to have a number of characteristics to be evaluated:

1. Qualitative $C P D$ : There would be minimal workload for the PHM Society to initiate and run but the practitioner's plan, documentation, and execution are open to question. Perhaps some guidance could be provided by the PHM Society.

2. Accredited CPD Award: A complete system would be high profile for the PHM Society but it would have the overhead of setting up and maintaining a system of relative values and maximum credits as well as a review process (with new and trained volunteers) to evaluate, approve/disapprove submitted documents.

\section{WAY FORWARD}

The PHM Society's Education and Professional Development Committee with the approval of the PHM Society Board would coordinate actions to:

a) Prepare and circulate a Discussion Note on Proposed PHM CPD Guidelines, including a reference document on the PHM Capabilities Taxonomy,

b) Lead a Workshop at the PHM Annual Conference to validate the concepts, discuss options, open issues and draft guidelines as well as an implementation approach, and

c) Develop a process for the PHM Society to implement the validated PHM CPD scheme.

\section{REFERENCES}

Bird, J., Madge, N., \& Reichard, K. (2014). Towards a capabilities taxonomy for prognostics and health management, IJPHM Communications, v. 5 no. 2.

Association of Professional Engineers and Geoscientists of Alberta (APEGA) (2014). Continuing Professional Development Program, April 2014. Accessed at: www.apega.ca/Regulatory/CPD/toc.html

American Medical Association (AMA) (2010). Continuing Medical Education. AMA Physician's Recognition Award Booklet, 2010. Accessed at:

http://www.ama-assn.org/ama/pub/educationcareers/continuing-medicaleducation.page?\&linkid=subnav-2

Federal Aviation Administration (FAA) (2009). William (Bill) O'Brien Aviation Maintenance Technician Awards Program Advisory Circular No: 65-25E Date: 6/3/09.

The Law Society of Alberta (2014). Continuing Professional Development. Accessed at: http://www.lawsociety.ab.ca/lawyers/cpd.aspx 
Pennsylvania Medical Society (PAMED). (2014) Continuing Medical Education. Accessed at: http://www.pamedsoc.org/MainMenuCategories/Educ ation/CME-Tracker/DO-CME-requirements.html

Vibration Institute (VI) (2014). Professional Development. Accessed at: http://www.vi-institute.org/professionaldevelopment/

\section{BIOGRAPHIES}

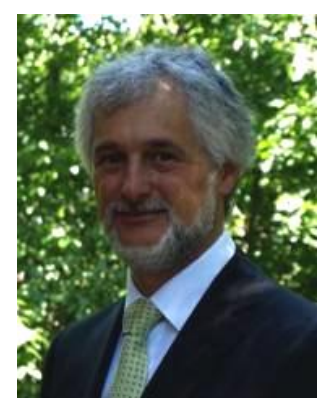

Jeff Bird is currently a consultant with TECnos Consulting Services, Ottawa, Canada. His present avocations include advancing the art, science and business of prognostics and health management in diverse fields. Specifically, he leads PHM Society board initiatives in Education and Professional Development as well as Standards.
He has the honour of serving as Vice President of the society now in a second term. He recently completed one career spanning 30 years as a Research Officer at the Gas Turbine Laboratory of the National Research Council Canada. His published research there included gas turbine dynamics and performance, health monitoring and management, adverse environments, and uncertainty. Previously he worked as an Operational Research officer in the Department of National Defence where he enjoyed contributing to airlift and search and rescue planning. $\mathrm{He}$ studied at the University of Toronto (Engineering ScienceAerospace) and at Carleton University (Mechanical, Aerospace and Systems) 